alarm among the members of the drug trade. A few of the more distinguished of the body considered (I believe with the best intention) that the excitement thus raised might be turned to a better account than the mere combination for trade-protection. The consequence of this was the formation of the Pharmacentical Society. A society so generonsly begun was believed to be the dawning of a new and better era among the followers of the chemical art.

The Society which promised so much at the beginning has been frittered into little more than a nest of snug berths, or rather, a small corporation of private interests. The society, it is true, is endowed with a system of free representation - a species of almost universal suffrage - and so may the Turks, Chinese, or Russians, in an equal sense, be said to have a free representative system, for in either case the expression of opinion is perfectly and wilfully in abeyance-an irresponsible and self-constituted authority rules alike in each instance over a self-isolated and indifferent multitude. So long as the Pharmaceutical Society remained in the humble, though useful, capacity of a private institution, the mere detail of its government would not have been a subject for the interference of any party not within its pale. By steady and stealthy steps, however, it is now seeking to place itself on the high ground of public authority. It proposes to avail itself of every possible power that the chemists may be kindly disposed to impart to it, nor does it promise them how speedily or tyrannically it will employ it. All this, says the editor of the Pharmaceutical Journal, "may be comprised in a few words, simply a bill to oblige all those who assume the rank of pharmaceutical chemists, and dispense the prescriptions of medical men, to qualify themselves to pass an examination." This must be done in a hurry too, for, says the editor, "the time has arrived when we must make a vigorous effort to complete the task which we have undertaken and in which we have made some progress." The time has also arrived, Sir, in which we must instantly and earnestly inquire whether this Pharmaceutical Society is so constituted as to be fit for the high functions which its rulers are panting to invest it with. The chief pretension it makes to public favour is founded on the fact of its having a museum, a library, a laboratory, and, above all, a school. Men must be educated, of course, before they can be examined. But who will be so lost to equity, propriety, or decency, as to accord the privilege of examining candidates and educating students to one and the same body of men? A pretty monopoly this, indeed! A fine machinery for the advancement of science this! Cramming, stuffing, grinding, sifting, winnowing, rejecting-all carried on on the premises. Is there no such Institution as the College of Chemistry?-no Royal Institution? no splendid chemical school? - no laboratory, except at 17, Bloomsbury-square? And what is to become of those unfortunate students who have not been blessed with an education in the pharmacentical school? How will they be able to get through their examination for the diploma? I libel not the motives of any man, or any body of men; but is it not to be expected, in the nature of things, that preference would be shown, and, like flowers turning to the sun, that pharmaceutical examiners should have a leaning towards a pharmaceutical school? The answers of THE LANCET upon such an institution as that of Blackfriars have been no less consistent than stringent; yet the most that Apothecaries' Hall has done, was to traffic in rhubarb while it was conferring degrees. Here, however, is a society that proposes to traffic, not only in degrees, but also in the education necessary to obtain them!taxing, as it were, both the manufacture and the raw material. If a trade is to be established by the education of chemists and druggists, they have a right to demand at least a free trade. But I emphatically pronounce, once for all, that as long as the Pharmaceutical Society shall be interested in the extension of their pharmaceutical school, they can have no fitness for the exercise of collegiate functions whose honours to their own students may be dispensed by favour rather than by merit, while they may prove to others only a mockery, a delusion, and a snare.

I remain, Sir, your obedient servant,

February, 18:6

H. B., Student in Chemistry.

* * Our correspondent has entirely misunderstood the proposal of the editor of the Pharmaceutical Journal, with respect to the "examination" of chemists and druggists, as the scheme evidently does not extend to persons who are now engaged in the business.-Ev. L.

\section{ON GRANULAR DEGENERATION OF THE KIDNEY.} To the Editor of THE LANCET.

SIR,-A paper was read one night some weeks back to the Medico-Chirurgical Society, announcing the existence of fatty accumulation in the lidney as the essential feature in the morbid anatomy of the so-called "granular degeneration" of that organ. The idea was put forward as one perfectly original and novel, and as such was it accepted by the assem. bled auditory. Now, waiving for the present the correctness of the idea, it may be as well to observe that I (and doubt. less many others, though the initiated did not figure among the learned professors of the practice of physic, \&c. in Berners Street on the night in question) have for upwards of four years been perfectly well acquainted with the circumstance, that unnatural fatty deposition in the renal substance constitutes the distinctive character of certain forms of the disease. And I came by my knowledge through a very simple process - that of reading. In the Second Part of Gluge's "Untersuchungen" it is thus written:-

"Second form of Bright's disease: Cirrhosis; deposition of fat globules in the cortical substance.

"First stage.-Deposition of free fat globules in the cortical substance, the vascular system of the kidney not being obviously affected.

"Second stage.-Deposition of yellow altered fat globules within the tubuli of the cortical substance. Bloodvessels unaffected. To this stage apparently belongs the case described by Valentin.

"Third stage.-Deposition of peculiar altered fat corpus. cles in regular rows in the site of the tubuli of the cortical substance, the tubuli themselves having been destroyed."*

So much for the originality of the idea; now for its correctness as an exclusive doctrine. I apprehend that any one, who has examined many kidneys of persons cut off with the symptoms of "renal dropsy," will have no difficnlty in rejecting the notion of the fatty nature of the disease as invariably consonant with fact. The truth is, that the minute anatomy of the kidney, when diseased in the mode to cause discharge of albuminous urine, anasarca, and all the well-known train of evils, varies in different cases. Gluge clearly saw this, and describes two other distinct kinds of morbid change as being present in certain cases. These kinds of change (his first and third forms) are, "inflammation" and "induration of undetermined form."

It is necessary to mention, that Gluge gives the details of numerous microscopical examinations, from which his general doctrine is derived.

I beg to subscribe myself, ONE WHO READS BEFore He "Discovers!"

Kensington, January, 1846 .

\section{ON THE EDUCATION OF DENTISTS.} To the Editor of The LANCET.

Sir,-You regretted, in the leading article of Thr Lancer of January 24, that circumstances have robbed the members of the Royal College of Surgeons of (according to your own estimate) the annual sum of $60,000 \mathrm{l}$. in London alone. What are the reasons that this branch of science has been lost to the general practitioner? It is from their own ignorance in the department, arising from a general disinclination of the profession to study more than that to which the dread of being plucked compels them, together with the certainty that to this subject no allusion is ever made in their examinations; add to this, the tendency arising from the increase of knowledge to a division of labour.

You point to Nasmyth and Bell as being surgeons. True, they are surgeons, and ornaments to the profession; but Mr. Bell got his knowledge of the profession which he follows, not from the College of Surgeons, but, after he had taken his degree, from one who is not a member of the Royal College. And talented as Mr. Bell is, both in his profession and in general scientific knowledge, he has, (as a practical dentist,) in the opinion of the many, his equal in one who is not of the college; (I need not add that I mean Mr. Cartwright.) There are others, also M.R.C. surgeons, practising as dentists, who, from their knowledge of the latter art alone, gathered from sources independent of the College, are ornaments to that College which gave them their diploma. But

* Anat-Mikroskop. Untersuchungen, ron G. Gluge, Zereites Heft, p. 130 , Tena, 1841 . 
for all this, still to be an M.R.C.S. is no criterion of capabilities to practise as a dentist; and there are many who (like myself) entered the profession first with the intention of being members of the Royal College, and to practise in that vocation, but who, when circumstances pointed out reasons for changing their profession, regretted that the College of Surgeons is no college for dentists.

The College of Surgeons is no college for dentists; but why can it not become so? The profession of the dentist is too far advanced, and too widely separated, ever again to become incorporated with the practice of the general practitioner: this is proved by the confidence which the professors of scientific diplomas have all over the country in the practice of the respectable dentist, who has nothing but his own abilities and experience to back him. But why, whilst now on the eve of the college legislation, cannot the profession of the dentist be collaterally allied with the College of Surgeons, and a school founded for the purpose? The dentists can support a school of their own; and surely the pen of The Lancer will not be slow in aiding that which must so greatly benefit the general weal, and guide in a path where I have no greater abilities than to hint "there is a way."

With every apology which you may think that it is necessary I should make for begging so much room,

I remain, Sir, your obedient servant

C. Spence Bate

Practising as a surgeon-dentist without being M.R.C.S.

\section{ON THE DIVISION OF FEES IN THE PRACTICE} OF MIDWIFERY.

To the Editor of THE LANCET.

SrR,- - Lately there have been several communications in your journal advocating the general adoption by the profession of a division of the midwifery fee in those cases where the gentleman engaged to attend happens to be absent at the birth of the child, and where another, being called in, is present. As I firmly believe that the adoption of such a regulation would be a positive injustice, and reflect great discredit on the profession, perhaps you will be good enough to find a place for a few reasons why it ought not to become general; why, indeed, such a practice ought to be at once discontinued; and why another mode of action, to my thinking much more just and honourable, ought to be substituted. In the first place, it must be recollected, that it is only in cases of great emergency that a stranger's attendance is required. Most of us have friends in our own neiglibourhood generally ready and willing to lend a helping hand in time of need; and if there are any not so fortunate, or if friends are engaged, and a stranger must be sent for, how stands the case generally ? Why, that the child is born, and the stranger liberated in half an hour. It very rarely falls to the lot of such men even as your suburban correspondent, to be under the necessity of remaining all night with a stranger's case. Moreover, midwifery fees are by no means unitorm in amount; and they are often intended to include, not only the actual attendance at the labour, whether it be long or short, but visits made both before and after. Could a conscientious man, then, quietly pocket half his professional brother's fee, when he must well know how small a portion of the trouble of the case fell to his share? It might be, as often happens, that the practitioner in attendance had been watching the case for days, and just at the critical moment he is unavoidably absent; another practitioner is called in, and the portion of the duty considered so important may be finished in ten minutes; and then, according to this new-fashioned, cormorant-like doctrine, he is to be rewarded with half the other's hard-earned fee, whatever may be its amount. Would this be justice? Would the acceptance of such proffered bounty be proper professional conduct? On the other hand, if a gentteman, not the usual attendant, were called to such a case of emergency as this, or, indeed, to any other case of emergency - for I would not limit the application of this principle to attendance on midwifery cases-and to claim of the friends a fee, in amount according to the circumstances of the case, would he not be doing his duty, and acting as a professional man ought? He would charge what he considered his due; he would not take from his professional brother what was fairly his; and the friends of the patient could not com plain at having to pay an additional fee for the services they required under such circumstances any more than they could in paying the fee of a consulting physician or surgeon. It may be said, there are many cases where the people are too poor to pay a second fee of any kind. In such cases, supposing the medical stranger added this good and gratuitous deed to the many others he is now called on to perform, would he not be more satisfied with such conduct than if he had taken the expected rights of another? I would not have it thought that I encourage the additional working of our ill-remunerated body without their just and proper remuneration; indeed, in my opinion, the plan now suggested would tend to teach people what at present they appear very ignorant of - that in calling in the services of a medical man they contract a debt as much as if they sent for a pound of tea without the money and I think a patient may as reasonably expect a general practitioner to pay the fees of a consultation out of his own pocket as to expect him to give up half his midwifery fee because certain circumstances have happened, over which he could have no control. If the friends of the patient thought the engaged attendant had neglected his duty, the proper punishment would lie in their hands, and they would not fail to inflict it; but $I$ see neither justice nor honourable feeling in the wish to mulct a brother practitioner of half his fee when he has done all in his power to perform the contract for which it was agreed to be paid. Not wishing to conceal a name, however humble, I beg to subscribe myself,

$$
\text { Sir, your obedient servant, }
$$

William RoBins.

Upper Southwick-street, Hyde-park, January, 1846.

\section{THE PREPARATION OF MEDICINES.}

To the Editor of THE LANCET.

Srr,-I shall feel obliged if you will enlighten me on the following point:-

The last proposition in the heads of Mr. Wakley's proposed Medical Bill runs thus: "The separation of the practice of physic and surgery from the sale of drugs and medicines."

$\mathrm{Am} I$ to understand from this that general practitioners are to be precluded from compounding their own medicines, or from keeping medicines in their houses? Is it intended or meant that whatever medicines they may prescribe shall, of necessity, be compounded by a licensed chemist and druggist? These gentry are most baneful to legally-qualified medical men. We have sixteen of them in this town, quacking away without the slightest hesitation or hindrance; indeed, they seem to laugh all qualified men to scorn.

$$
\text { I am, Sir, your very obedient servant, }
$$

5, Cheapside, Halifax, Feb. 1846.

Fredekick S. Gariuck.

* * It never can, in any Medical Bill, be seriously proposed to "preclude general practitioners from compounding medicines, or keeping medicines in their houses," nor "compel them to have their prescriptions compounded by licensed chemists and druggists." It would be a strong measure to prevent medical practitioners from recovering at law, charges for medicines which they may supply to their patients. Such an interdict even as this could not be sustained except on urgent grounds of professional and public necessity.-ED. $L$.

\section{MERCURY AND IODINE IN SECONDARY SYPHILIS.}

To the Editor of THE LuNCET.

Sra,-From my experience in this country and in Paris, $I$ am fully convinced of the truth of the four propositions enunciated by Mr. Acton on this question, at page 119 of your journal. I think the principle of alternation the only one to be relied upon-that is, if the primary symptoms have been mercurially treated, the secondary will require iodine, and a relapse of these, or tertiary if they occur, must again be visited with some form, generally a mild one, of mercury, and vice versa.

I have lately had three cases of secondary symptoms under my care, where the primary affection had been treated with mercury, and in all these cases this mineral had failed to procure any relief in the constitutional symptoms, though exhibited in every form, from that of mercury and chalk to that of the bichloride. All these cases yielded at once to the iodide of potassium.

With reference to the dose of this salt, $I$ find six or eight grains in combination with half that weight of carbonate of potass, more effectual than twelve grains without that alkali. 